\title{
Genetic Variation Within and Among Lowland Switchgrass Cultivars as Revealed with AFLP Polymorphisms
}

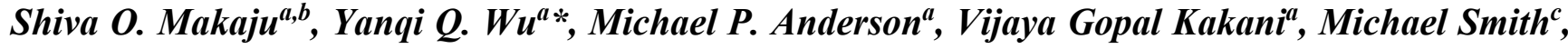 \\ James Todd ${ }^{\text {, and Laxman Adhikari }}{ }^{e}$
}

${ }^{a}$ Plant and Soil Sciences Department, Oklahoma State University, Stillwater, OK 74078

${ }^{b}$ Center for Applied Genetic Technologies, University of Georgia, Athens, GA 30602

${ }^{c}$ Horticulture and Landscape Architecture Department, Oklahoma State University, Stillwater, OK 74078

${ }^{d}$ USDA-ARS, Sugarcane Research Unit, Houma, LA 70360

${ }^{e}$ Department of Plant Pathology, Kansas State University, Manhattan, KS 66506

\section{MANUSCRIPT INFO}

Article history:

Received 21 February 2020

Revised 12 March 2020

Accepted 15 April 2020

\section{Keywords:}

AFLP

genetic variation

lowland switchgrass

bioenergy crop

\begin{abstract}
A B S T R A C T
Switchgrass (Panicum virgatum $\mathrm{L}$.) has gained wider attention due to its recognition and use as a model herbaceous crop species for bioenergy production. Genetic diversity information in lowland switchgrass cultivars can help to specify cultivars to be used in the breeding programs aiming for hybrid vigor. The objective of this research was to analyze genetic variation within and among five lowland switchgrass cultivars using amplified fragment length polymorphism (AFLP) markers. AFLP polymorphisms indicated the presence of high genetic variation within lowland switchgrass cultivars with 'Alamo' exhibiting the highest genetic variation and 'Performer' the lowest. The Nei's genetic diversity parameters revealed the lowest genetic distance between cultivars 'Alamo' and 'Cimarron' and the highest value between cultivars 'Alamo' and 'Kanlow'. 'Alamo' and 'Cimarron' were clustered together while 'BoMaster', 'Kanlow', and 'Performer' were grouped into the other cluster. In addition, there were clusters with mixed genotypes. The findings of this study can be used to select diverse lines as parents for heterosis and inbreeding studies.
\end{abstract}

(C) 2020 NAPA. All rights reserved.

\section{Citation:}

Makaju, S. O., Wu, Y. Q., Anderson, M. P., Kakani, V. G., Smith, M, Todd, J. \& Adhikari, L. (2020). Genetic Variation Within and Among Lowland Switchgrass Cultivars as Revealed with AFLP Polymorphisms. Global Journal of Agricultural and Allied Sciences, 2(1), 11-17.

\section{Introduction}

Switchgrass (Panicum virgatum L.) is a highly polymorphic and wind pollinated polyploid species with disomic inheritance (Liu \& Wu, 2012; McLaughlin \& Kszos, 2005; Nielsen, 1944; Okada et al., 2010; Taliaferro, 2002). Lowland and upland are two ecotypes in switchgrass and the ploidy level in switchgrass has been reported from diploid $(2 n=2 x=18)$ to duodecaploid $(2 \mathrm{n}=12 \mathrm{x}=108)$ (Adhikari, Anderson, Klatt \& Wu, 2015; Nielsen, 1944). Ploidy level in switchgrass is characteristic of ecotype. The lowland ecotypes are tetraploid $(2 n=4 x=36)$ but the upland ecotypes can be tetraploid $(2 n=4 x=36)$ or octaploid $(2 n=8 x=72)$ or very rarely hexaploids $(2 \mathrm{n}=6 \mathrm{x}=54)$ (Narasimhamoorthy, Saha, Swaller \& Bouton, 2008; Nielsen, 1944). Aneuploidy has been reported to be more common in higher ploidy levels, i.e., octaploid (86.3\%) than in lower ploidy levels, i.e., tetraploids (23.2\%) (Costich, Friebe, Sheehan, Casler \& Buckler, 2010). Switchgrass has a reference genome, assembled for the cultivar Alamo (AP13), which is approximately $1,165.7 \mathrm{Mb}$ in size and includes 98,935 complete genes

\footnotetext{
*Corresponding author. E-mail address: yanqi.wu@okstate.edu
}

(https://phytozome.jgi.doe.gov/pz/portal.html\#!info?alias=Org_Pvirgatum _er).

Genetic diversity is the result of selection, mutation, migration, genetic drift and/or recombination (de Vicente \& Fulton, 2003). Variation can be evaluated on phenotypic and/or genotypic levels. Genotypic variation is evaluated at the level of DNA molecules responsible for transmitting genetic information (de Vicente \& Fulton, 2003). DNA markers simply refer to a DNA sequence in the genome that can be used to genotype individuals or a population. The markers are selected based on the nucleic acid hybridization (RFLP), PCR (RAPD, AFLP, SSR), single base-pair change [single nucleotide polymorphisms (SNP)], array hybridization [diversity arrays technology (DArT)], and restriction site associated DNA (RAD).

Different molecular markers have been used in the switchgrass diversity studies. They include random amplified polymorphic DNA (RAPD) (Casler, Stendal, Kapich \& VOgel, 2007; Gunter, Tuskan \& Wullschleger, 1996; Nageswara-Rao, Soneji Kwit \& Stewart, 2013), restriction fragment length polymorphism (RFLP) (Missaoui, Paterson \& Bouton, 2006), expressed sequence tag-simple sequence repeat markers (EST-SSRs) 
(Cortese, Honig, Miller \& Bonos, 2010; Huang, Bughrara, Zhang, BalesArcelo \& Bin, 2011; Narasimhamoorthy et al., 2008), amplified fragment length polymorphism (AFLP) (Todd et al., 2011), simple sequence repeats (SSR) (Zalapa et al., 2011), sequence-related amplified polymorphism (SRAP) (Huang et al., 2011) and a network-based single nucleotide polymorphism (SNP) (Lu et al., 2013). SNP markers were used in the switchgrass genetic diversity analysis to identify seven population groups that corresponded to ecotype, ploidy, and geographic distribution (Evans et al., 2017). AFLP markers can delineate between upland and lowland ecotypes and related plants according to broad geographic regions (Todd, Wu, Wang \& Samuels, 2011). SSR markers were used to delineate diversity between ecotypes and between ploidy levels (Zhang et al., 2011). RFLP markers were used to determine extensive diversity between lowland tetraploid cultivar 'Alamo' (AP13) and upland tetraploid cultivar 'Summer' (VS16) and to develop linkage maps (Missaoui, Paterson \& Bouton, 2005, 2006).

The information on the extent of diversity in lowland cultivars will help determine the specific cultivars to be used in future crop improvement programs to develop potentially high yielding switchgrass cultivars. The immediate benefit of such diversity information will be in the development of advanced inbreds [selfing generations 5 to 6 (S5 to S6)] which can be used to produce hybrids for harnessing hybrid vigor. Bhandari, Nayak, Dalid \& Sykes (2017) found up to $23 \%$ high parent heterosis from a cross between selections of divergent populations of switchgrass. Inbred populations can be utilized in the development of linkage maps (Liu, Wu, Wang \& Samuels, 2012) and identification of quantitative trait loci (QTL) associated with agronomic, quality and disease traits. The QTL information can then be used in the marker assisted selection in switchgrass breeding.

Polymerase chain reaction (PCR) is a simple, automated technique for repeated copying of a short DNA molecule (Conner \& Hartl, 2004). AFLP is a PCR based dominant marker and used in genetic research, DNA fingerprinting, and genetic engineering (Vos et al., 1995). It is a highly sensitive method for detecting polymorphisms in DNA. Unlike SNP genotyping, AFLP genotyping lack the information regarding the DNA sequence, which hinders in comparative genome analysis such as coregulation of markers or orthologous gene studies using common techniques such as nucleotide BLAST. However, AFLP is still a proven method that at low cost without specialized equipment can generate many bands. It has been successful at accessing genetic diversity and linkage mapping in many crops around the world (Meudt \& Clarke, 2007). Because information on genetic diversity with outcrossing lowland switchgrass populations is generally lacking, this study aimed to analyze genetic diversity among and within five lowland switchgrass cultivars using AFLP. The cultivars included 'Alamo', 'BoMaster', 'Cimarron', 'Kanlow', and 'Performer'.

\section{Study Methods}

\subsection{Plant Materials and Genomic DNA Extraction}

Plant materials consisted of 384 plants from five lowland tetraploid cultivars 'Alamo', 'BoMaster', 'Cimarron', 'Performer', and 'Kanlow'. Seventy-six plants from the cultivar 'Performer' and 77 plants from each of the remaining four cultivars were seed-propagated and transplanted in individual 10-cm plastic pots with SUN-GRO Metro-Mix 200 series soil (Sun Gro Horticulture, WA) in a greenhouse at the Agronomy Research Station, Oklahoma State University, Stillwater, OK. The study began in
July 2011 and completed in December 2013. Genomic DNA samples were extracted from leaf tissues using Zymo Research ZR Plant/Seed DNA Kit ${ }^{\mathrm{TM}}$ (Zymo Research Corporation, CA). DNA quality was checked with $1 \%$ agarose gel electrophoresis. The DNA samples were diluted to a final concentration of $100 \mathrm{ng} \mu \mathrm{L}^{-1}$ before enzyme digestion.

In the study for genetic variation among five cultivars, a total of 64 plants were used including 12 plants from cultivar 'Performer' and 13 plants from each of the remaining four cultivars (Fig. 1). The within genetic variation was studied separately for each of the five cultivars with 64 plants in each of them. The decision to use the above-mentioned numbers were based on capacity of polyacrylamide gel which can accommodate 64 sample lanes and two additional size marker lanes in a LI-COR 4300 DNA Analyzer.

\subsection{AFLP Analysis}

AFLP analysis was performed following Vos et al. (1995), with minor modifications (Todd et al., 2011; Wu, Taliaferro, Bai \& Anderson, 2005). In the first step, the genomic DNA was double-digested with EcoRI and MSeI restriction enzymes and the DNA fragments were ligated to oligonucleotide AFLP adapters. The ligated DNA fragments were preamplified by PCR using a primer combination based on adapter sequences. In the second step, 12 AFLP selective primer combinations (Table 1) were used for selective amplification. The EcoRI primers were labeled with either IRD-700 or IRD-800 infrared fluorescence dye. The number of polymorphic bands (loci) considered appropriate for genetic variation in switchgrass is $>400$ (Todd et al., 2011). Accordingly, 12 selective primer pairs were used to generate $>400$ amplification products (polymorphic loci). All PCRs were conducted in an Applied Biosystems 2720 thermocycler (Applied Biosystems Inc., IL). In the third step, approximately one microliter of selectively amplified PCR products were loaded on a $0.25 \mathrm{mM}$ thick $6.5 \%(\mathrm{w} / \mathrm{v})$ polyacrylamide gel with 66 wells in a LI-COR 4300 DNA Analyzer (LI-COR Inc., Lincoln, NE) and run in 1x TBE buffer at $1500 \mathrm{~V}$ for $2.5 \mathrm{~h}$. Standard DNA size markers (50-700 bp) (LI-COR Inc., Lincoln, NE) were loaded on first and last lanes to determine the size of the selectively amplified fragments in the final gel image. A total of 36 gels including 6 gels for among cultivar genetic variation and 30 gels (6 gels for each of the five cultivars) for within cultivar genetic variation were run.

\subsection{Data Analysis}

AFLP bands throughout the gel profile were visually scored as present (1), absent (0), and ambiguous (9). The scoring is repeated at least twice for all gel profiles to accurately collect data. The bands were scored between $\sim 75$ and $500 \mathrm{bp}$. The binary data matrix was recorded in a Microsoft Excel data sheet. Numerical Taxonomy System version 2.0 (NTSYSpc 2) program (Rohlf, 1998) was used to analyze the data. Each gel gave two images based on IRD-700 or IRD-800 infrared fluorescence dye. Data from six gels (12 images) were used for among-cultivar variation study. Data from six gels (12 images) for each of the five cultivars were separately analyzed for the within-cultivar variation analysis. A total of 72 gel images, including 12 gel images for among genetic variation and 60 gel images for within genetic variation, were scored and analyzed. In NTSYSpc 2 program, SIMQUAL module was used to compute genetic similarity coefficients (SC). The cluster analysis was based on unweighted pair-group method with arithmetic mean (UPGMA) within the SAHN module. DCENTER module was used for the principle coordinate analysis. 
Table 1. Polymorphic band information with 12 different AFLP selective amplification primer pairs for five cultivars together (among cultivars) and within each of the five cultivars separately.

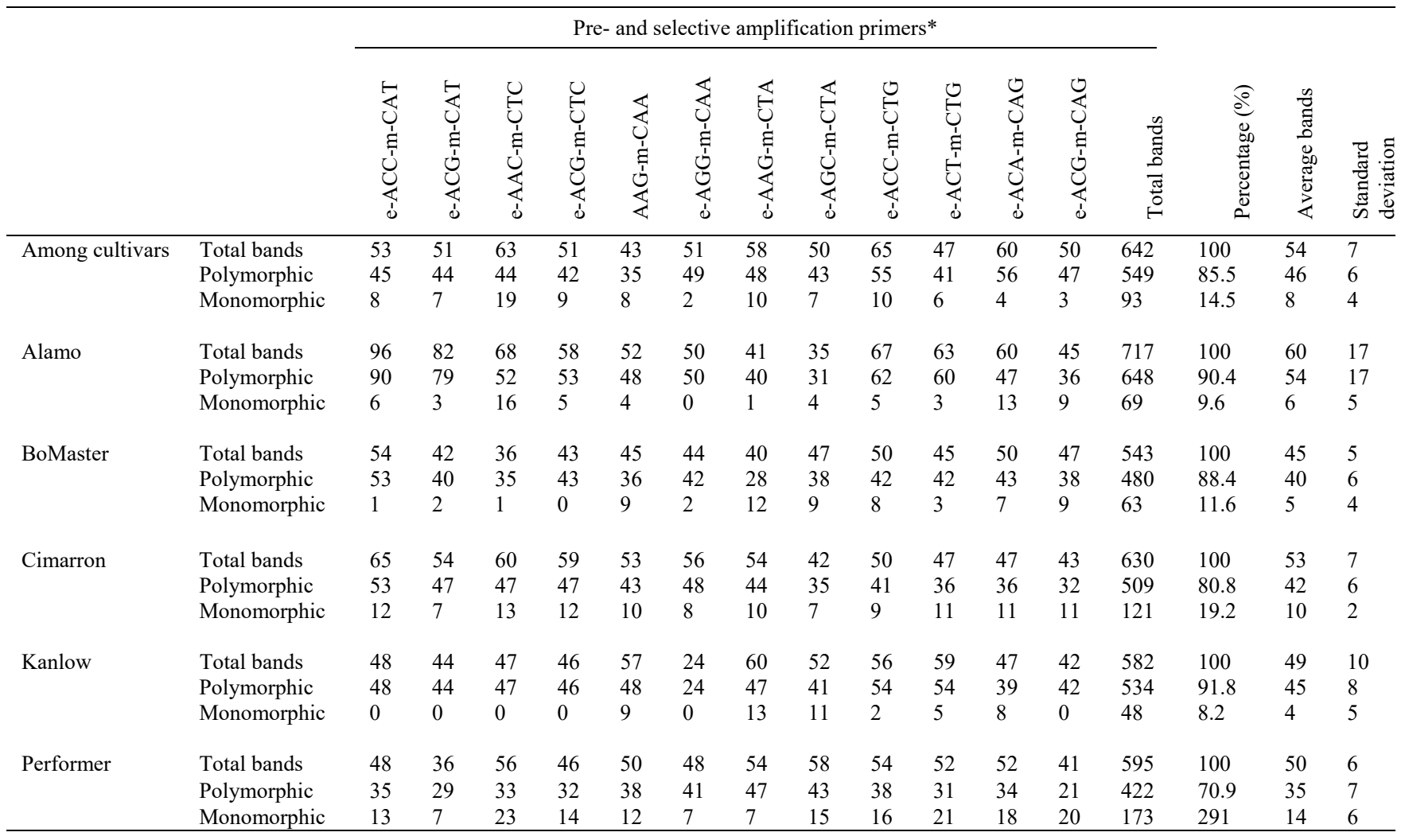

* e, preamplification primer of EcoRI (GACTGCGTACCAATTC); m, preamplification primer of MseI (GATGAGTCCTGAGTAA)

Table 2. Similarity coefficient comparison for five lowland switchgrass cultivars based on similarity coefficient tables.

\begin{tabular}{|c|c|c|c|c|c|c|}
\hline & $\begin{array}{l}\text { Among } \\
\text { cultivars }\end{array}$ & Alamo & BoMaster & Cimarron & Kanlow & Performer \\
\hline Average & 0.76 & 0.79 & 0.82 & 0.79 & 0.76 & 0.82 \\
\hline Standard deviation & 0.05 & 0.08 & 0.07 & 0.05 & 0.04 & 0.03 \\
\hline Maximum & 0.88 & 0.89 & 0.98 & 0.90 & 0.88 & 0.90 \\
\hline Minimum & 0.60 & 0.41 & 0.48 & 0.60 & 0.59 & 0.69 \\
\hline Coefficient of variation & 5.96 & 9.53 & 8.03 & 5.70 & 5.82 & 4.21 \\
\hline Maximum between & $\mathrm{K} 18$ and $\mathrm{K} 20$ & $\begin{array}{l}\text { A33 and A36; and } \\
\text { A35 and A36 }\end{array}$ & B74 and B75 & $\mathrm{C} 27$ and $\mathrm{C} 28$ & $\mathrm{~K} 39$ and $\mathrm{K} 40$ & $\begin{array}{l}\text { P56 and P57; P65 and P69; P76 and } \\
\text { P77 }\end{array}$ \\
\hline Minimum between & $\mathrm{A} 4$ and $\mathrm{P} 4$ & $\mathrm{~A} 9$ and $\mathrm{A} 72$ & B5 and B45 & $\mathrm{C} 23$ and $\mathrm{C} 50$ & $\mathrm{~K} 7$ and $\mathrm{K} 88$ & $\begin{array}{l}\mathrm{P} 30 \text { and } \mathrm{P} 49 ; \mathrm{P} 30 \text { and } \mathrm{P} 51 ; \mathrm{P} 30 \text { and } \\
\mathrm{P} 57 ; \mathrm{P} 30 \text { and } \mathrm{P} 61 ; \mathrm{P} 30 \text { and P64 }\end{array}$ \\
\hline
\end{tabular}

Table 3. Summary of Shannon's information index (I), expected heterozygosity (He), and unbiased expected heterozygosity (uHe) for five different cultivars of lowland switchgrass.

\begin{tabular}{|c|c|c|c|c|c|c|}
\hline \multirow[b]{2}{*}{ Cultivar } & \multicolumn{2}{|l|}{ I } & \multicolumn{2}{|l|}{$\mathrm{He}$} & \multicolumn{2}{|l|}{ uHe } \\
\hline & Mean & SE & Mean & SE & Mean & SE \\
\hline Alamo & 0.425 & 0.008 & 0.277 & 0.006 & 0.280 & 0.006 \\
\hline BoMaster & 0.412 & 0.010 & 0.269 & 0.007 & 0.271 & 0.007 \\
\hline Cimarron & 0.373 & 0.010 & 0.243 & 0.007 & 0.245 & 0.007 \\
\hline Kanlow & 0.444 & 0.009 & 0.292 & 0.007 & 0.294 & 0.007 \\
\hline Performer & 0.345 & 0.011 & 0.227 & 0.008 & 0.229 & 0.008 \\
\hline
\end{tabular}






Figure 1. AFLP fingerprints generated for five lowland switchgrass cultivars ('Alamo', 'BoMaster', 'Cimarron', 'Kanlow', and 'Performer') using primer combination e-ACC-m-CTG. The fragment size (bp) is indicated on the right and the cultivars are indicated at the bottom of the image.

Shannon's information index (I), expected heterozygosity (He), and unbiased expected heterozygosity (uHe) were computed separately for each of the five cultivars; analysis of molecular variance (AMOVA) and Nei's genetic distance (Nei 1972) calculation were performed in among-variation data. GenAlEx 6 (Peakall \& Smouse, 2012, Peakall \& Smouse, 2006) software was used for these computations. AFLP bands initially scored as present (1), absent (0), and ambiguous (9) for NTSYSpc 2 were converted into present (1), absent (0), and ambiguous/missing (-1) for calculations in GenAlEx 6. AMOVA was performed to partition variation between cultivars. Pairwise genetic distance in different cultivars was computed using Nei's distance (Nei, 1972).

\section{Results}

Table 1 shows polymorphic band data with 12 different selective amplification primer pairs used in the experiment. In the analysis among five cultivars together, $85.5 \%$ of bands were polymorphic (Table 1). In the analysis within each of the five cultivars separately, polymorphic band percentages ranged from a minimum of $70.9 \%$ in 'Performer' to a maximum of $91.8 \%$ in 'Kanlow'. Similarity coefficients from analysis among five cultivars were given in Table S1 and the summary of similarity coefficients, for among cultivars and for each of the five cultivars, was provided in Table 2 .

'Alamo' exhibited the highest within-cultivar genetic variation (coefficient of variation=9.53) and 'Performer' exhibited the lowest withincultivar genetic variation (coefficient of variation=4.21) (Table 2). Analysis using five cultivars together showed 'A4' from 'Alamo' and 'P4' from 'Performer' were the most divergent (similarity coefficient $=0.60$ ) (Table 2 and Table S1). The average similarity coefficient ranged from 0.76 to 0.82 indicating the presence of high genetic variation among switchgrass genotypes.

The cluster analysis on AFLP variation among five cultivars generated a dendrogram with big cluster $(\mathrm{m})$ which included 61 genotypes from different cultivars and a small cluster (n) that included genotypes P4, P6, and P8 from cultivar 'Performer' (Fig. 2). A genotype C4 from cultivar 'Cimarron' was observed separate from the rest of the individuals in the big cluster. The cluster $\mathrm{m}$ produced a cluster $(\mathrm{m}-1)$ of mixed genotypes from 'Alamo', 'BoMaster', and 'Cimarron' and a cluster (m-2) with two subclusters ( $a$ and $b$ ). The sub-cluster ' $a$ ' included cultivars 'Alamo' (a-1) and 'Cimarron' (a-2) while the sub-cluster 'b' included 'BoMaster' (b-1), 'Kanlow' (b-2), and 'Performer' (b-3). In the sub-cluster 'b', 'BoMaster' and 'Kanlow' were genetically more similar. The two-dimensional plot from principal coordinates analysis produced groupings (Fig. S1) mostly consistent with the clusters generated from the cluster analysis. The principal coordinates analysis revealed that the first principal coordinate explained $10.34 \%$ variation and the second principal coordinate explained $7.85 \%$ variation. The dendrograms from cluster analysis and twodimensional plots from principal coordinates analysis are mostly congruent for AFLP variation within each of the five cultivars 'Alamo', 'BoMaster', 'Cimarron', 'Kanlow', and 'Performer' (Figs. S2, S3, S4, S5, S6, S7, S8, S9, S10, S11). In these five cultivars, the first principal coordinate explained $11.80,9.38,8.09,7.98$, and $11.40 \%$ variations, respectively, 
while the second principal coordinate explained 5.90, 6.27, 5.61, 5.72, and $4.33 \%$ variations, respectively.

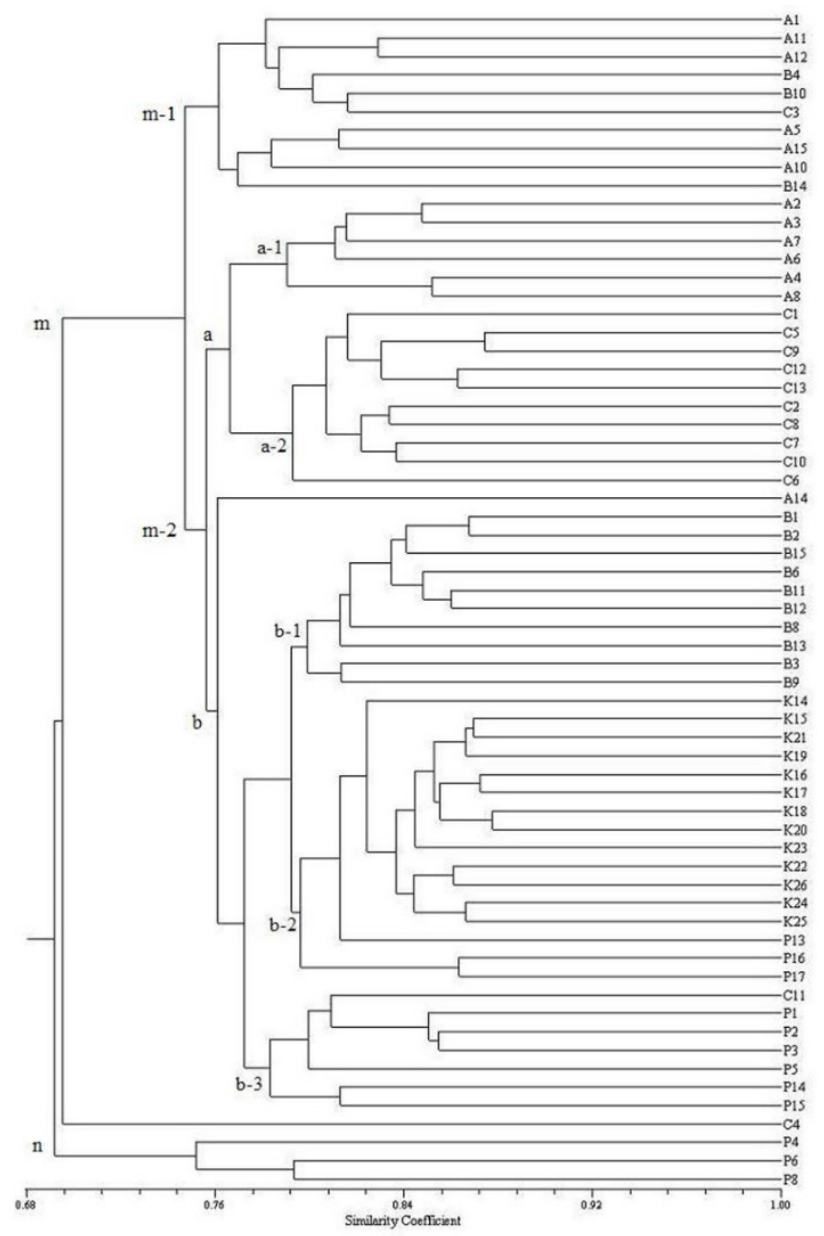

Figure 2. UPGMA tree of similarity coefficients (dendrogram) obtained from AFLP variation among five lowland switchgrass cultivars. A, B, C, K, and P represent cultivars 'Alamo', 'BoMaster', 'Cimarron', 'Kanlow', and 'Performer', respectively.

Mantel test results are shown in Table S2. The goodness of fit of the dendrograms to the original dissimilarity matrices (i.e., similarity coefficient table) was poor for among-cultivars (analysis of five cultivars together) and for 'Kanlow', however, the dendrograms were not significantly different from dissimilarity matrices $(P=1>0.05$ in both cases). The dendrograms were a good or a very good fit to the dissimilarity matrices for each of 'Alamo', 'BoMaster', 'Cimarron', and 'Performer'.

AMOVA analysis carried out in the data from AFLP variation among five lowland switchgrass cultivars partitioned variation between cultivars at $15 \%$ as estimated variances and degrees of freedom (df) between cultivars, within cultivar, and total were 13.34 and 4, 74.39 and 59, and 87.73 and 63 , respectively. Nei's genetic diversity revealed the lowest genetic distance between cultivars 'Alamo' and 'Cimarron' and the highest value between cultivars 'Alamo' and 'Kanlow' (Table S3). Shannon's information index (I), expected heterozygosity (He), and unbiased heterozygosity $(\mathrm{uHe})$ calculated separately for each of the five cultivars revealed higher values for 'Kanlow' and 'Alamo' compared to the other three cultivars (Table 3 ).

\section{Discussion}

The morphological and physiological variation in switchgrass is closely associated with climatic factors and the adaptation along north-south range is dependent on photoperiod (Casler, 2012). Switchgrass is a native crop from North America with a large morphological diversity and wider adaptation (Parrish \& Fike, 2005). The cultivars 'Alamo' and 'Kanlow' were developed from wild germplasm sources. 'Alamo' (PI 422006) was the cultivar collected from George West, TX (U.S. National Plant Germplasm System, 2014) and 'Kanlow' was initially collected in 1957 at a lowland site near Wetumka, OK (U.S. National Plant Germplasm System, 2014). 'Kanlow' (PI 421521) accession was developed as a cultivar by a cooperative effort of Kansas Agricultural Experiment Station (AES) and Plant Science Research Division, Agricultural Research Service (ARS) and was released in 1963 .

The original ancestor of cultivar 'Cimarron' was primarily from 'Alamo'. 'Cimarron' was developed as a synthetic cultivar by polycrossing seven elite clonal parents in 2001 at Oklahoma State University (Wu, 2014). The selection of parent plants for 'Cimarron' was based on the evaluation of biomass yield of their half-sib families ( $\mathrm{Wu}, 2014)$. The dendrogram and two-dimensional plot showed 'Alamo' and 'Cimarron' in the same group exhibiting the genetic relatedness consistent with the pedigree information. It appears that lowland switchgrass can be divided into two broad populations, including those from the south related to 'Alamo' like 'Cimarron' and the northern populations related to 'Kanlow' such as 'BoMaster' and 'Performer'. It was between these populations, 'Alamo' and 'Kanlow', that midparent heterosis was found and one of the crosses showed 23\% high parent heterosis (Bhandari et al., 2017).

'BoMaster' and 'Performer' switchgrass cultivars were developed by North Carolina Agricultural Research Service, NC. Both 'BoMaster' (Reg. No. CV-248, PI 645256) (Burns, Godshalk \& Timothy, 2008a) and 'Performer' (Reg. No. CV-247) (Burns, Godshalk \& Timothy, 2008b) switchgrass cultivars were developed through three cycles of selection from a selected group of 161 lowland switchgrass plants that represented 11 different germplasm sources which included 'Kanlow'. The method in the development of these cultivars was recurrent half-sib selection. The selection for both cultivars was based on dry matter yield and in vitro dry matter digestibility. 'BoMaster' was selected for dry matter yield (Burns et al., 2008a) and 'Performer' was for in vitro dry matter digestion (Burns et al., 2008b) during the cultivar development. Similarly, the dendrogram and the two-dimensional plot showed 'Kanlow', 'BoMaster', and 'Performer' in the same group. The seven population groups identified in a genetic diversity analysis include Upland West, Upland East, Upland North, Upland Montane, Lowland North, Lowland South, Lowland Central, and admixed (Evans et al., 2017), indicating the genetic diversity across NorthSouth and across East-West. 'Alamo', 'Cimarron', and 'Kanlow' were originated in George West in Texas, Stillwater in Oklahoma, and Wetumka in Oklahoma, respectively. 'BoMaster' and 'Performer' both were 
originated in Raleigh in North Carolina. The variation among these cultivars can also be attributed to the switchgrass genetic diversity across North-South and East-West locational gradients. Self-incompatibility and inter-cultivar gene flow, the characteristics of switchgrass, can also be the possible attributing factors for the clusters of mixed genotypes. We have used genetic distance based on AFLP markers as the basis to separate cultivars as heterotic. However, a further study may be required to determine if AFLP genetic distance is correlated with heterosis.

\section{Conclusions and Recommendations}

Lowland tetraploid switchgrass cultivars showed a high level of genetic variation. 'Alamo' showed the highest genetic variation while 'Performer' showed the lowest. The plant 'A4' from 'Alamo' and the plant 'P4' from 'Performer' were the most divergent genotypes. 'Alamo' and 'Cimarron' were clustered together while 'BoMaster', 'Kanlow', and 'Performer' were grouped into the other cluster. In addition, there were clusters with mixed genotypes as well. The findings of this research would be useful for future plant breeding and genetic improvement programs in lowland switchgrass. The results can be used for the selection of diverse lines as parents for heterosis and inbreeding studies.

\section{Acknowledgements}

The research was in part funded by NSF-EPSCoR: Award No. NSF/EPS0814361 and Oklahoma Agricultural Experiment Station. The authors would like to appreciate Dr. Tilin Fang, Mrs. Pu Feng, Dr. Hongxu Dong, Dr. Chengcheng Tan, Dr. Yuanwen Guo and Ms. Shuiyi Thames for their support in this research.

\section{References}

Adhikari, L., Anderson, M. P., Klatt, A., \& Wu, Y. (2015). Testing the efficacy of a polyester bagging method for selfing switchgrass. BioEnergy Research, 8(1), 380-387.

Bhandari, H. S., Nayak, S., Dalid, C. O., \& Sykes, V. R. (2017). Biomass yield heterosis in lowland switchgrass. Crop Science, 57(4), 2015-2023.

Burns, J., Godshalk, E., \& Timothy, D. (2008a). Registration of 'BoMaster' switchgrass. Journal of plant registrations, 2(1), 31-32.

Burns, J., Godshalk, E., \& Timothy, D. (2008b). Registration of 'Performer' switchgrass. Journal of plant registrations, 2(1), 29-30.

Casler, M. D. (2012). Switchgrass breeding, genetics, and genomics. In: A. Monti (Ed.), Switchgrass (pp: 29-53). London, UK: Springer.

Casler, M. D., Stendal, C. A., Kapich, L., \& Vogel, K. P. (2007). Genetic diversity, plant adaptation regions, and gene pools for switchgrass. Crop Science, 47(6), 2261-2273.

Conner, J., \& Hartl, D. (2004). A primer of ecological genetics. Sunderland, MA: Sinauer Associates, Inc.

Cortese, L. M., Honig, J., Miller, C., \& Bonos, S. A. (2010). Genetic diversity of twelve switchgrass populations using molecular and morphological markers. BioEnergy Research, 3(3), 262-271.

Costich, D. E., Friebe, B., Sheehan, M. J., Casler, M. D., \& Buckler, E. S. (2010). Genome-size variation in switchgrass (Panicum virgatum): flow cytometry and cytology reveal rampant aneuploidy. The Plant Genome, 3(3), 130-141. de Vicente, M. C., \& Fulton, T. (2003). Using molecular marker technology in studies on plant genetic diversity. Retrieved from https://www.bioversityinternational.org/fileadmin/user_upload/online_libr ary/publications/pdfs/Molecular_Markers_Volume_1_en.pdf.

Evans, J., Sanciangco, M. D., Lau, K. H., Crisovan, E., Barry, K., Daum, C., . . . Buell, C. R. (2017). Extensive genetic diversity is present within North American switchgrass germplasm. The Plant Genome, 11, 1-16.

Gunter, L., Tuskan, G., \& Wullschleger, S. (1996). Diversity among populations of switchgrass based on RAPD markers. Crop Science, 36(4), 1017-1022.

U.S. National Plant Germplasm System, 2014. Panicum virgatum L. Retrieved August 25, 2014,

from https://npgsweb.arsgrin.gov/gringlobal/accessiondetail.aspx?id=1318052.

Huang, L. K., Bughrara, S., Zhang, X. Q., Bales-Arcelo, C. J., \& Bin, X. (2011). Genetic diversity of switchgrass and its relative species in Panicum genus using molecular markers. Biochemical Systematics and Ecology, 39(4-6), 685-693.

Liu, L., \& Wu, Y. (2012). Identification of a selfing compatible genotype and mode of inheritance in switchgrass. BioEnergy Research, 5(3), 662-668.

Liu, L., Wu, Y., Wang, Y., \& Samuels, T. (2012). A High-Density Simple Sequence Repeat-Based Genetic Linkage Map of Switchgrass. G3: Genes|Genomes|Genetics, 2(3), 357-370. doi:10.1534/g3.111.001503.

Lu, F., Lipka, A. E., Glaubitz, J., Elshire, R., Cherney, J. H., Casler, M. D., . . . Costich, D. E. (2013). Switchgrass genomic diversity, ploidy, and evolution: novel insights from a network-based SNP discovery protocol. PLoS Genetics, 9(1), e1003215.

McLaughlin, S. B., \& Kszos, L. A. (2005). Development of switchgrass (Panicum virgatum) as a bioenergy feedstock in the United States. Biomass and Bioenergy, 28(6), 515-535.

Meudt, H. M., \& Clarke, A. C. (2007). Almost forgotten or latest practice? AFLP applications, analyses and advances. Trends Plant Science, 12, 106117.

Missaoui, A. M., Paterson, A. H., \& Bouton, J. H. (2005). Investigation of genomic organization in switchgrass (Panicum virgatum L.) using DNA markers. Theoretical and Applied Genetics, 110(8), 1372-1383. doi:10.1007/s00122-005-1935-6

Missaoui, A. M., Paterson, A. H., \& Bouton, J. H. (2006). Molecular markers for the classification of switchgrass (Panicum virgatum $\mathrm{L}$.) germplasm and to assess genetic diversity in three synthetic switchgrass populations. Genetic Resources and Crop Evolution, 53(6), 1291-1302. doi:10.1007/s10722-005-3878-9.

Nageswara-Rao, M., Soneji, J. R., Kwit, C., \& Stewart, C. N. (2013). Advances in biotechnology and genomics of switchgrass. Biotechnology for Biofuels, 6(1), 77.

Narasimhamoorthy, B., Saha, M., Swaller, T., \& Bouton, J. (2008). Genetic diversity in switchgrass collections assessed by EST-SSR markers. BioEnergy Research, 1(2), 136-146.

Nei, M. (1972). Genetic Distance between Populations. The American Naturalist, 106(949), 283-292. Retrieved from http://www.jstor.org/stable/2459777.

Nielsen, E. L. (1944). Analysis of variation in Panicum virgatum. Journal of Agricultural Resources, 69, 327-53.

Okada, M., Lanzatella, C., Saha, M. C., Bouton, J., Wu, R., \& Tobias, C. M. (2010). Complete switchgrass genetic maps reveal subgenome collinearity, preferential pairing and multilocus interactions. Genetics, 185(3), 745-760.

Parrish, D. J., \& Fike, J. H. (2005). The biology and agronomy of switchgrass for biofuels. Critical Reviews in Plant Sciences. 24: 423-459.

Peakall, R. \& Smouse, P. E. (2012). GenAlEx 6.5: genetic analysis in Excel. Population genetic software for teaching and research - an update. Bioinformatics, 28, 2537-2539. 
Peakall, R. \& Smouse, P. E. (2006). GenAlEx 6: genetic analysis in Excel. Population genetic software for teaching and research. Molecular Ecology Resources, 6(1), 288-295.

Rohlf, F. J. (1998). NTSYS-pc: numerical taxonomy and multivariate analysis system, version. 2.02i. Applied Biostatistics, Inc., Setauket, New York, NY.

Taliaferro, C. M. (2002). Breeding and selection of new switchgrass varieties for increased biomass production. ORNL Technical Report ORNL/SUB02-19XSY162C/01. Oak Ridge National Laboratory, Oak Ridge, Tennessee.

Todd, J., Wu, Y., Wang, Z., \& Samuels, T. (2011). Genetic diversity in tetraploid switchgrass revealed by AFLP marker polymorphisms. Genetics and Molecular Research, 10(4), 2976-2986.

Vos, P., Hogers, R., Bleeker, M., Reijans, M., Lee, T. v. d., Hornes, M., . . . Zabeau, M. (1995). AFLP: a new technique for DNA fingerprinting. Nucleic acids research, 23(21), 4407-4414.
$\mathrm{Wu}, \mathrm{Y} .(2014)$. Classic genetics and breeding of bioenergy related traits in switchgrass. In H. Luo, Y. Wu, \& C. Kole (Eds.), Compendium of Bioenergy Plants: Switchgrass (pp. 170). Boca Raton, FL: CRC Press of Taylor and Francis Group.

Wu, Y., Taliaferro, C., Bai, G., \& Anderson, M. (2005). Genetic diversity of Cynodon transvaalensis Burtt-Davy and its relatedness to hexaploid $C$. dactylon (L.) Pers. as indicated by AFLP markers. Crop Science, 45(3), 848-853.

Zalapa, J., Price, D., Kaeppler, S., Tobias, C., Okada, M., \& Casler, M. (2011). Hierarchical classification of switchgrass genotypes using SSR and chloroplast sequences: ecotypes, ploidies, gene pools, and cultivars. Theoretical and Applied Genetics, 122(4), 805-817.

Zhang, Y., Zalapa, J. E., Jakubowski, A. R., Price, D. L., Acharya, A., Wei, Y., ... Casler, M. D. (2011). Post-glacial evolution of Panicum virgatum: centers of diversity and gene pools revealed by SSR markers and cpDNA sequences. Genetica, 139(7), 933. doi:10.1007/s10709-011-9597-6. 
Figure S1. Principal coordinates analysis for AFLP variation among five cultivars. A, B, C, K, and P represent cultivars 'Alamo', 'BoMaster', 'Cimarron', 'Kanlow', and 'Performer', respectively. PC-1 and PC-2 are two major principal coordinate axes.

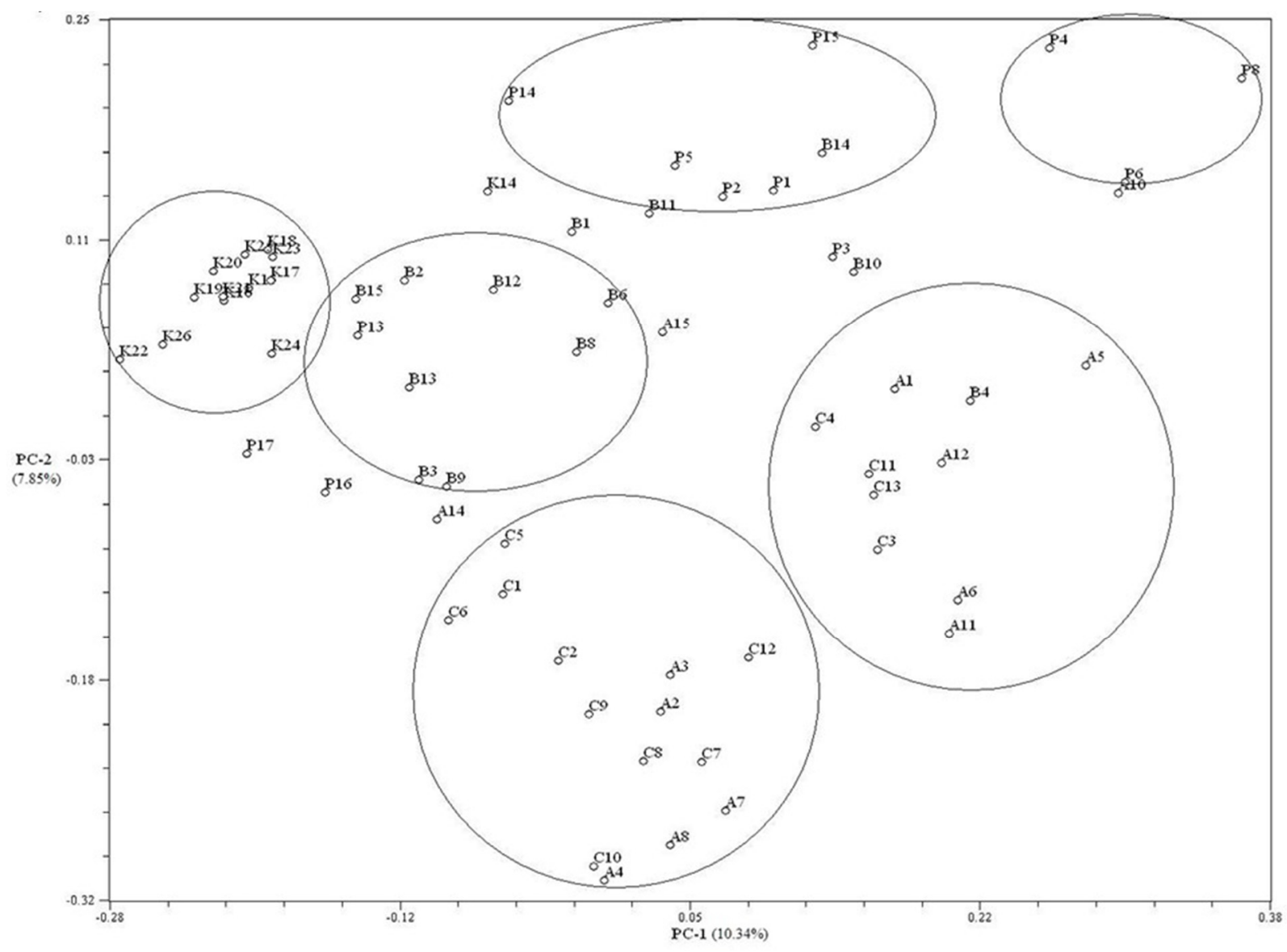


Figure S2. UPGMA tree of similarity coefficients (dendrogram) obtained from AFLP variation within cultivar 'Alamo'. A represents cultivar 'Alamo'.

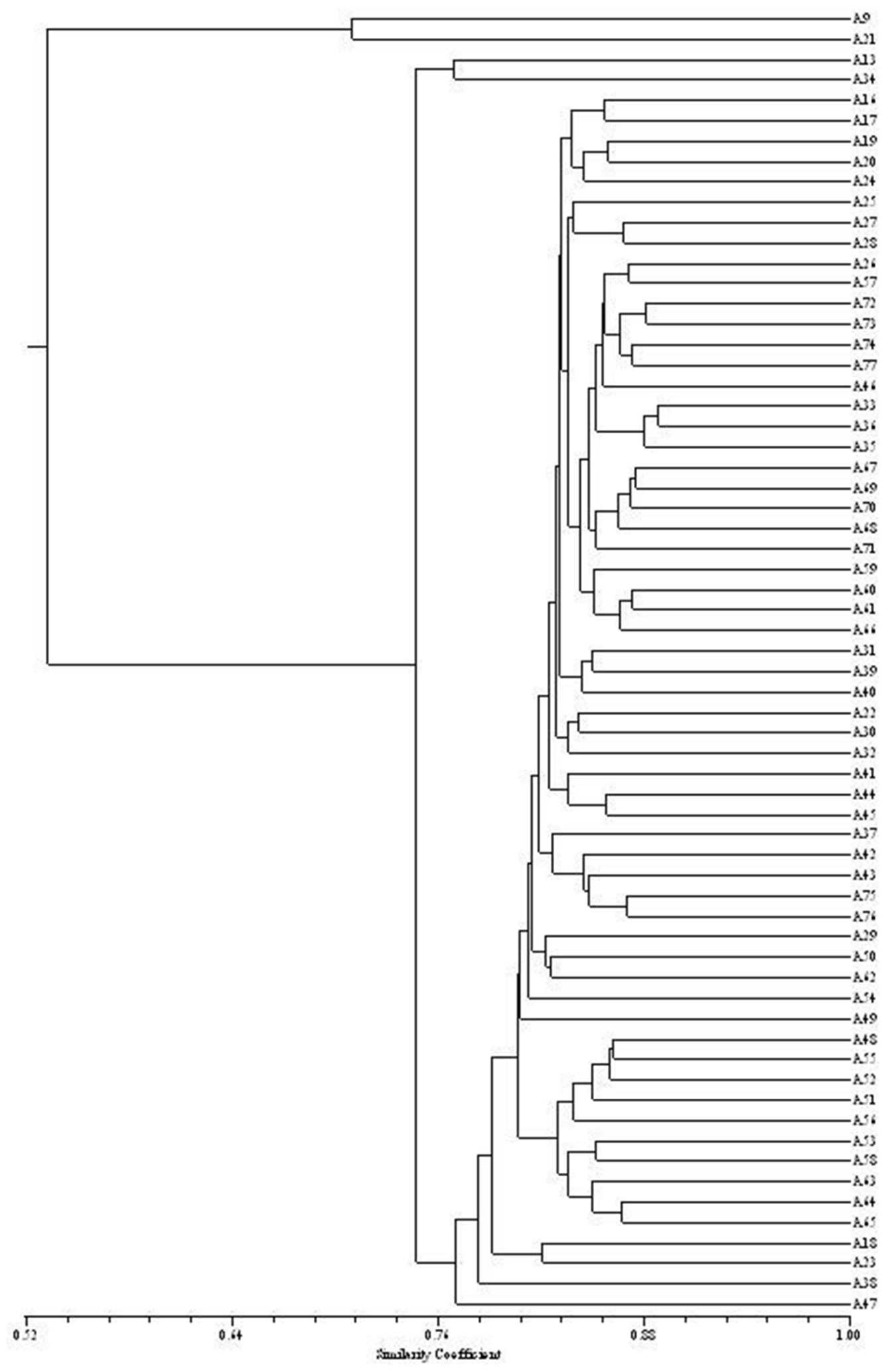


Figure S3. UPGMA tree of similarity coefficients (dendrogram) obtained from AFLP variation within cultivar 'BoMaster'. B represents cultivar 'BoMaster'.




Figure S4. UPGMA tree of similarity coefficients (dendrogram) obtained from AFLP variation within cultivar 'Cimarron'. C represents cultivar 'Cimarron'.




Figure S5. UPGMA tree of similarity coefficients (dendrogram) obtained from AFLP variation within cultivar 'Kanlow'. K represents cultivar 'Kanlow'.

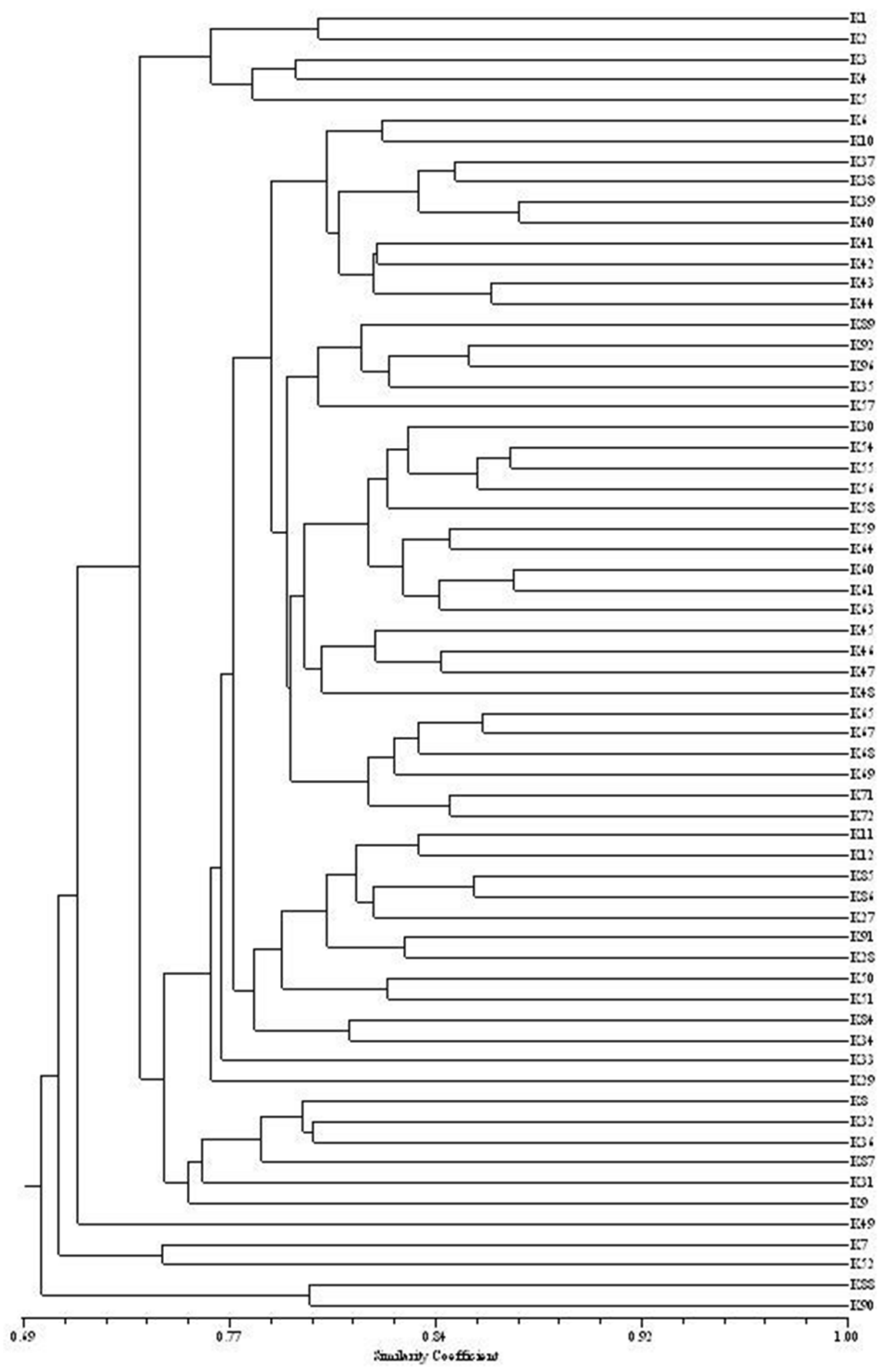


Figure S6. UPGMA tree of similarity coefficients (dendrogram) obtained from AFLP variation within cultivar 'Performer'. P represents cultivar 'Performer'.

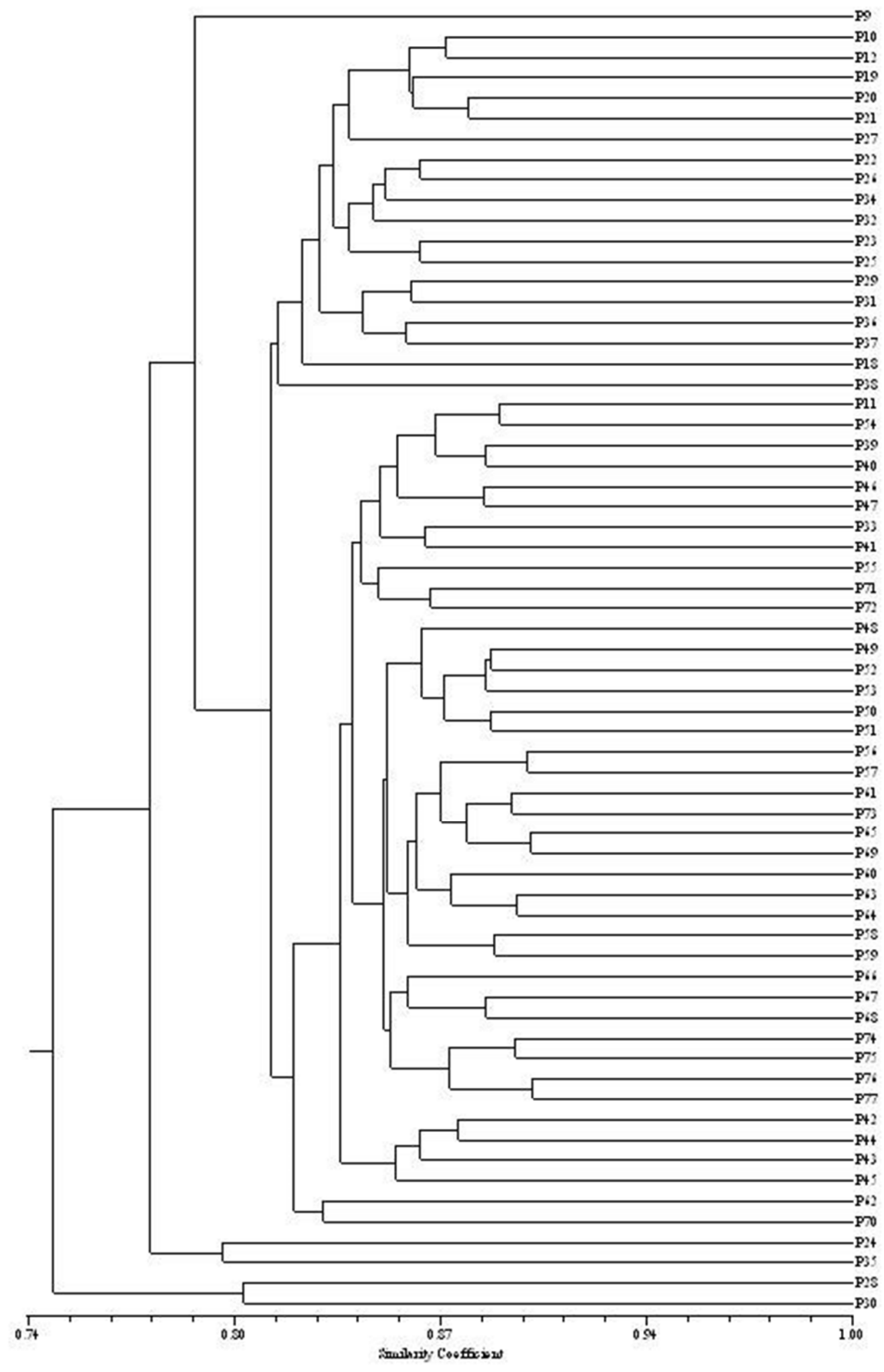


Figure S7. Principal coordinates analysis in 'Alamo'. PC-1 and PC-2 are two major principal coordinate axes.

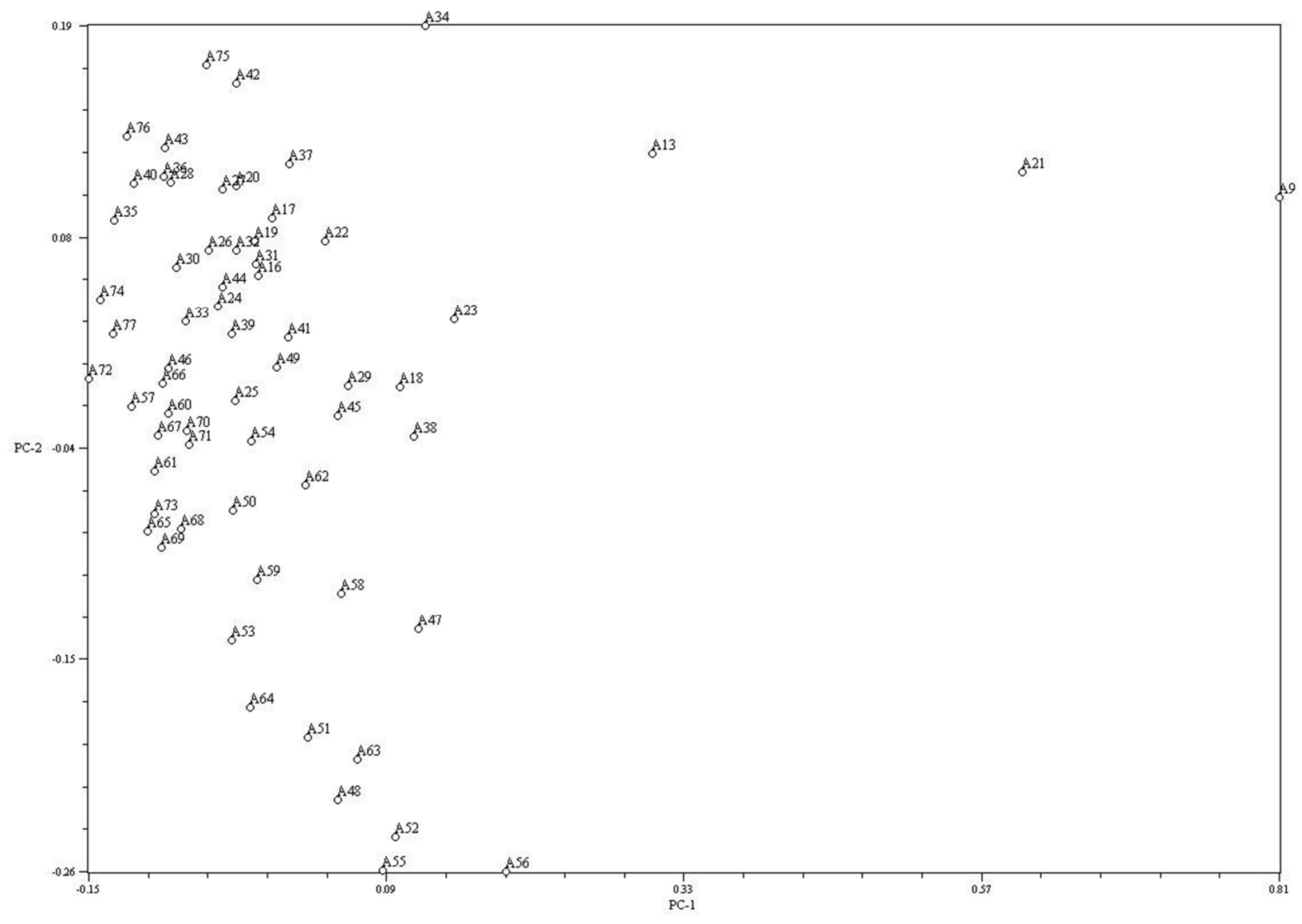


Figure S8. Principal coordinates analysis in 'BoMaster'. PC-1 and PC-2 are two major principal coordinate axes.

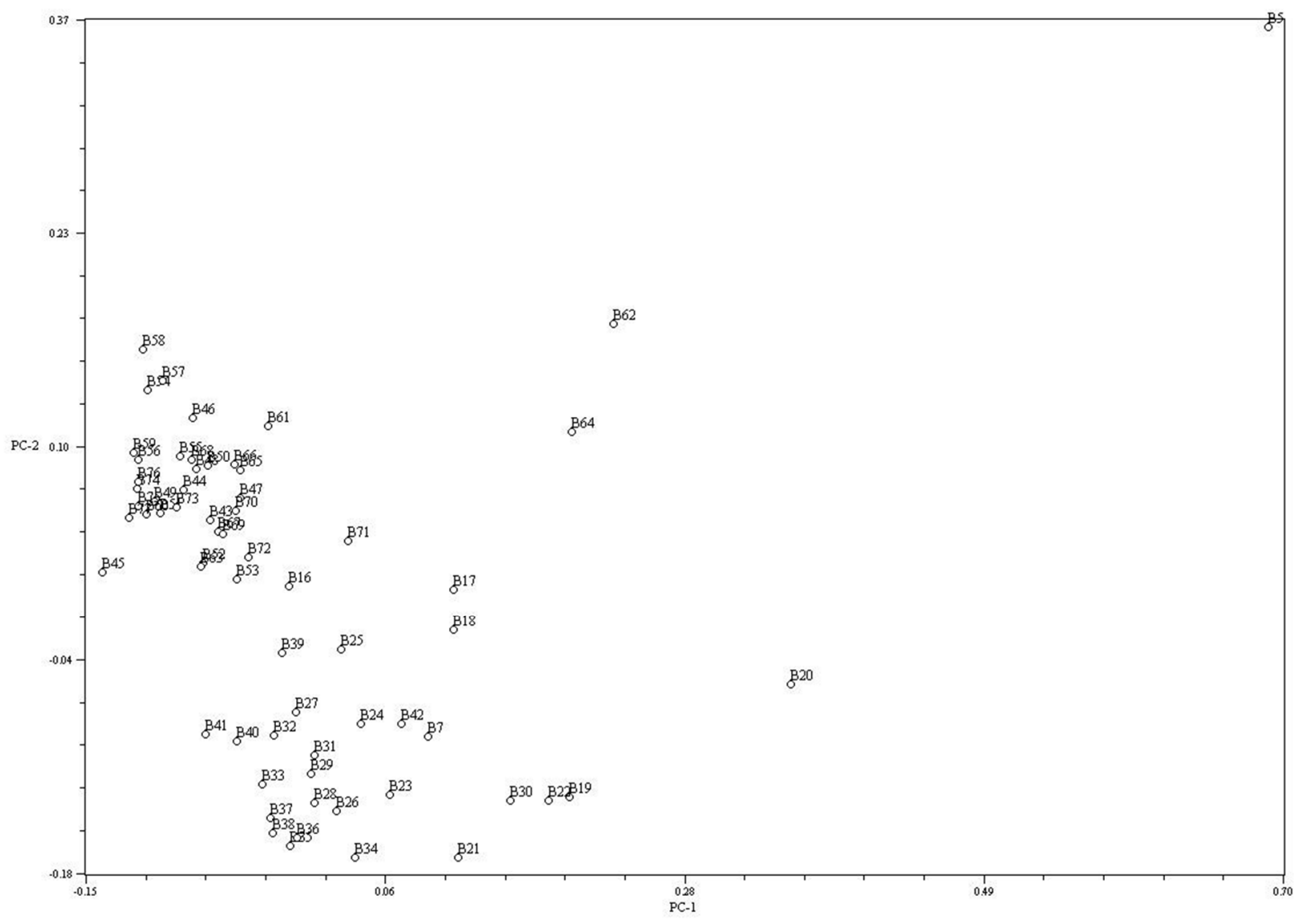


Global Journal of Agricultural AND Allied ScienCEs 2(1):11-17 (2020)

Figure S9. Principal coordinates analysis in 'Cimarron'. PC-1 and PC-2 are two major principal coordinate axes.

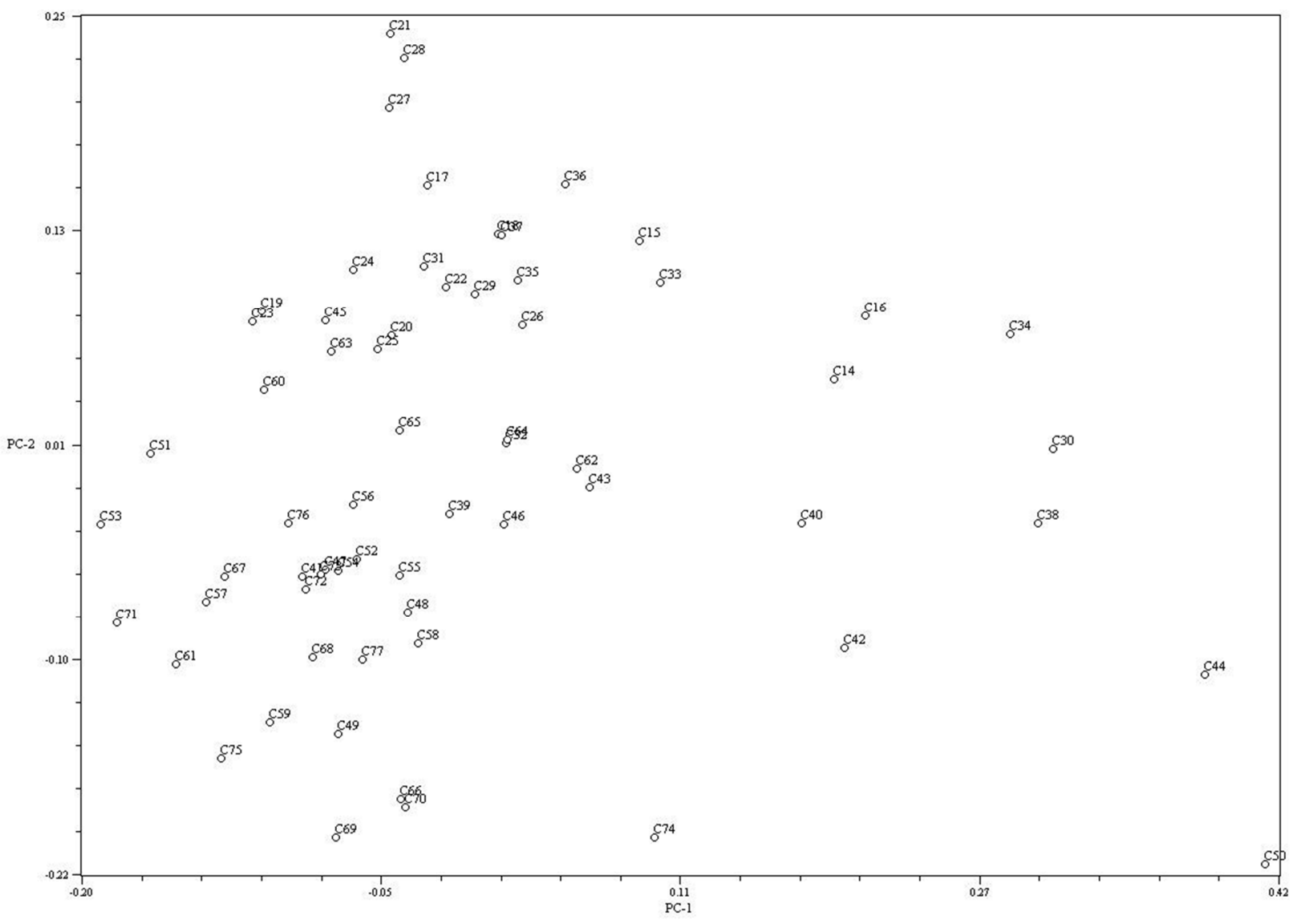


Global Journal of Agricultural AND Allied ScIENCES 2(1):11-17 (2020)

Figure S10. Principal coordinates analysis in 'Kanlow'. PC-1 and PC-2 are two major principal coordinate axes.

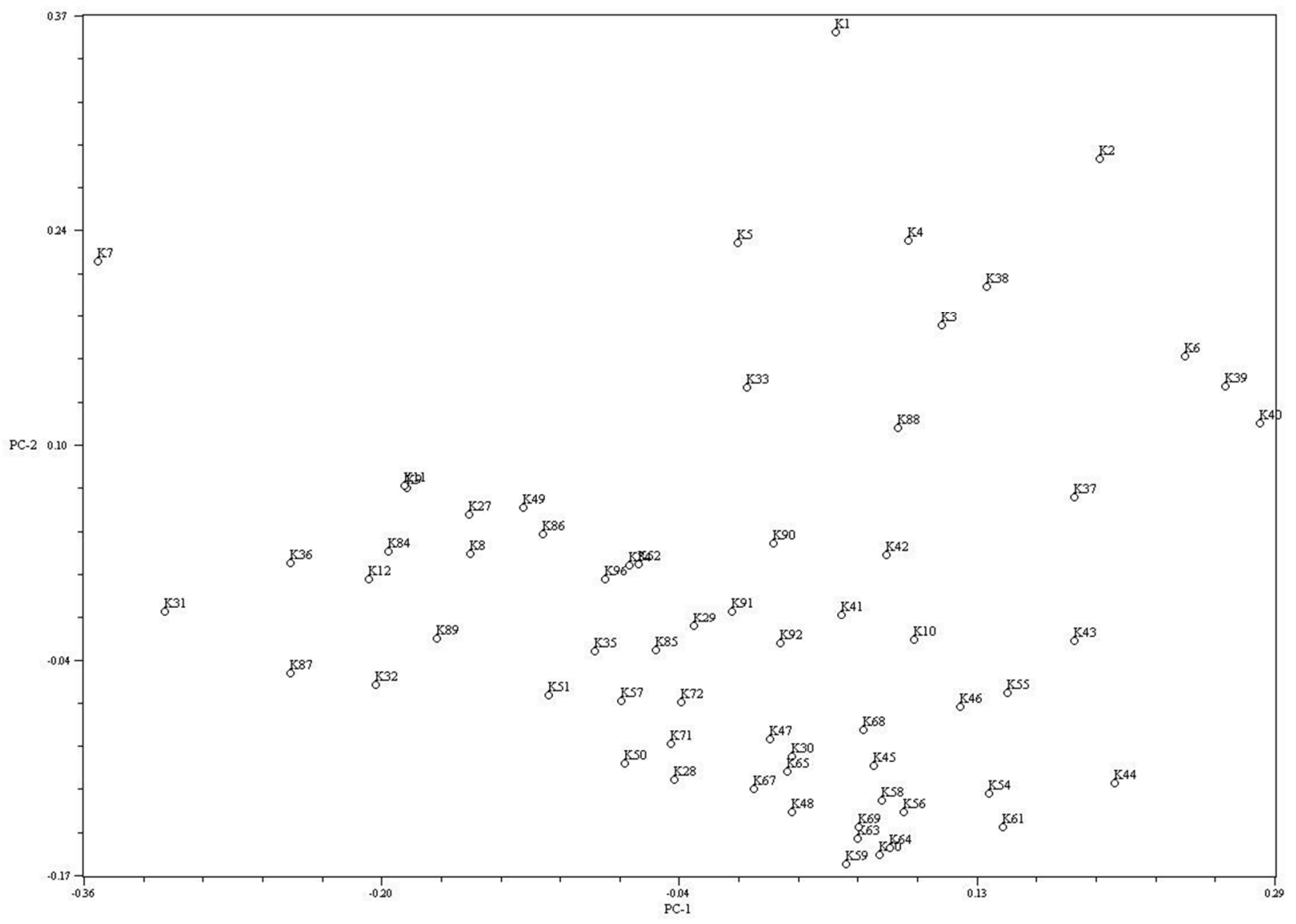


Global Journal of Agricultural AND AlLied ScIENCES 2(1):11-17 (2020)

Figure S11. Principal coordinates analysis in 'Performer'. PC-1 and PC-2 are two major principal coordinate axes.

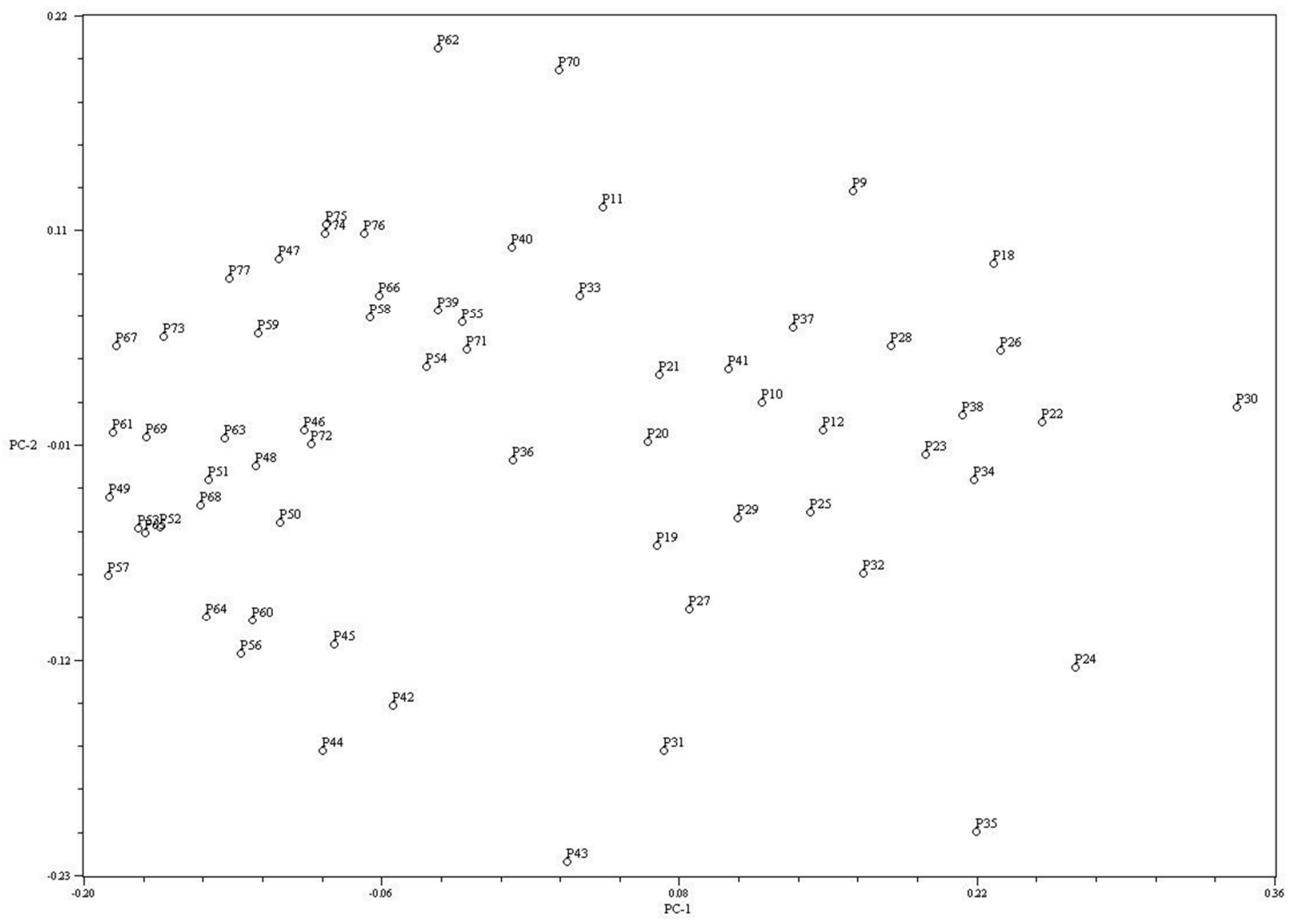


Table S1. Similarity coefficients among five lowland switchgrass cultivars. The ID for each plant genotype was denoted by a combination of letter and number. A, B, C, K, and P represented cultivars 'Alamo', 'BoMaster', 'Cimarron', 'Kanlow', and 'Performer', respectively (contd.)

\begin{tabular}{|c|c|c|c|c|c|c|c|c|c|c|c|c|c|c|c|c|c|c|c|c|c|c|c|c|c|c|c|c|c|c|c|c|}
\hline & A1 & A2 & $\mathbf{A 3}$ & A4 & A5 & A6 & A7 & A8 & A10 & A11 & A12 & A14 & A15 & B1 & B2 & B3 & B4 & B6 & B8 & B9 & B10 & B11 & B12 & B13 & B14 & B15 & C1 & C2 & C3 & $\mathrm{C} 4$ & C5 & C6 \\
\hline$\overline{\mathrm{A} 1}$ & 1.00 & & & & & & & & & & & & & & & & & & & & & & & & & & & & & & & \\
\hline A2 & 0.74 & 1.00 & & & & & & & & & & & & & & & & & & & & & & & & & & & & & & \\
\hline A3 & 0.77 & 0.85 & 1.00 & & & & & & & & & & & & & & & & & & & & & & & & & & & & & \\
\hline A4 & 0.69 & 0.79 & 0.80 & 1.00 & & & & & & & & & & & & & & & & & & & & & & & & & & & & \\
\hline A5 & 0.77 & 0.74 & 0.73 & 0.73 & 1.00 & & & & & & & & & & & & & & & & & & & & & & & & & & & \\
\hline A6 & 0.77 & 0.81 & 0.82 & 0.78 & 0.79 & 1.00 & & & & & & & & & & & & & & & & & & & & & & & & & & \\
\hline A7 & 0.72 & 0.81 & 0.82 & 0.81 & 0.72 & 0.81 & 1.00 & & & & & & & & & & & & & & & & & & & & & & & & & \\
\hline A8 & 0.72 & 0.77 & 0.79 & 0.85 & 0.71 & 0.80 & 0.79 & 1.00 & & & & & & & & & & & & & & & & & & & & & & & & \\
\hline A10 & 0.78 & 0.69 & 0.70 & 0.65 & 0.81 & 0.74 & 0.69 & 0.67 & 1.00 & & & & & & & & & & & & & & & & & & & & & & & \\
\hline A11 & 0.78 & 0.78 & 0.79 & 0.75 & 0.74 & 0.80 & 0.79 & 0.73 & 0.74 & 1.00 & & & & & & & & & & & & & & & & & & & & & & \\
\hline A12 & 0.79 & 0.77 & 0.79 & 0.76 & 0.78 & 0.81 & 0.78 & 0.75 & 0.77 & 0.83 & 1.00 & & & & & & & & & & & & & & & & & & & & & \\
\hline A14 & 0.72 & 0.76 & 0.77 & 0.78 & 0.72 & 0.72 & 0.73 & 0.77 & 0.67 & 0.70 & 0.73 & 1.00 & & & & & & & & & & & & & & & & & & & & \\
\hline A15 & 0.76 & 0.77 & 0.76 & 0.74 & 0.81 & 0.76 & 0.75 & 0.73 & 0.76 & 0.73 & 0.76 & 0.79 & 1.00 & & & & & & & & & & & & & & & & & & & \\
\hline B1 & 0.75 & 0.76 & 0.76 & 0.74 & 0.75 & 0.76 & 0.74 & 0.72 & 0.73 & 0.75 & 0.78 & 0.77 & 0.79 & 1.00 & & & & & & & & & & & & & & & & & & \\
\hline B2 & 0.76 & 0.76 & 0.77 & 0.74 & 0.74 & 0.76 & 0.75 & 0.73 & 0.73 & 0.74 & 0.78 & 0.76 & 0.80 & 0.87 & 1.00 & & & & & & & & & & & & & & & & & \\
\hline B3 & 0.73 & 0.74 & 0.76 & 0.75 & 0.72 & 0.73 & 0.73 & 0.76 & 0.68 & 0.73 & 0.74 & 0.76 & 0.75 & 0.80 & 0.81 & 1.00 & & & & & & & & & & & & & & & & \\
\hline B4 & 0.75 & 0.72 & 0.74 & 0.71 & 0.76 & 0.76 & 0.73 & 0.71 & 0.74 & 0.74 & 0.79 & 0.71 & 0.73 & 0.78 & 0.76 & 0.77 & 1.00 & & & & & & & & & & & & & & & \\
\hline B6 & 0.78 & 0.77 & 0.77 & 0.74 & 0.75 & 0.77 & 0.75 & 0.74 & 0.74 & 0.76 & 0.79 & 0.73 & 0.77 & 0.84 & 0.84 & 0.82 & 0.79 & 1.00 & & & & & & & & & & & & & & \\
\hline B8 & 0.73 & 0.75 & 0.79 & 0.74 & 0.75 & 0.76 & 0.74 & 0.74 & 0.70 & 0.72 & 0.78 & 0.76 & 0.78 & 0.81 & 0.84 & 0.79 & 0.79 & 0.81 & 1.00 & & & & & & & & & & & & & \\
\hline B9 & 0.73 & 0.74 & 0.74 & 0.75 & 0.74 & 0.73 & 0.74 & 0.78 & 0.70 & 0.71 & 0.74 & 0.76 & 0.76 & 0.76 & 0.79 & 0.81 & 0.76 & 0.81 & 0.81 & 1.00 & & & & & & & & & & & & \\
\hline B10 & 0.80 & 0.75 & 0.78 & 0.73 & 0.79 & 0.78 & 0.74 & 0.74 & 0.80 & 0.77 & 0.81 & 0.74 & 0.78 & 0.82 & 0.81 & 0.78 & 0.81 & 0.84 & 0.79 & 0.81 & 1.00 & & & & & & & & & & & \\
\hline B11 & 0.76 & 0.74 & 0.76 & 0.74 & 0.77 & 0.76 & 0.74 & 0.73 & 0.77 & 0.75 & 0.80 & 0.76 & 0.78 & 0.83 & 0.84 & 0.78 & 0.77 & 0.86 & 0.82 & 0.80 & 0.84 & 1.00 & & & & & & & & & & \\
\hline B12 & 0.78 & 0.75 & 0.75 & 0.75 & 0.73 & 0.76 & 0.74 & 0.75 & 0.74 & 0.75 & 0.78 & 0.74 & 0.77 & 0.82 & 0.85 & 0.79 & 0.76 & 0.84 & 0.81 & 0.82 & 0.81 & 0.86 & 1.00 & & & & & & & & & \\
\hline B13 & 0.73 & 0.76 & 0.75 & 0.73 & 0.70 & 0.73 & 0.73 & 0.73 & 0.69 & 0.71 & 0.74 & 0.73 & 0.74 & 0.80 & 0.81 & 0.81 & 0.74 & 0.83 & 0.79 & 0.80 & 0.78 & 0.80 & 0.83 & 1.00 & & & & & & & & \\
\hline B14 & 0.75 & 0.73 & 0.73 & 0.68 & 0.77 & 0.77 & 0.69 & 0.67 & 0.77 & 0.72 & 0.77 & 0.71 & 0.77 & 0.78 & 0.78 & 0.74 & 0.75 & 0.80 & 0.75 & 0.73 & 0.80 & 0.80 & 0.79 & 0.80 & 1.00 & & & & & & & \\
\hline B15 & 0.72 & 0.77 & 0.78 & 0.75 & 0.71 & 0.76 & 0.75 & 0.74 & 0.70 & 0.73 & 0.77 & 0.78 & 0.79 & 0.82 & 0.86 & 0.80 & 0.73 & 0.84 & 0.81 & 0.79 & 0.77 & 0.84 & 0.83 & 0.82 & 0.80 & 1.00 & & & & & & \\
\hline C1 & 0.75 & 0.75 & 0.76 & 0.76 & 0.73 & 0.75 & 0.77 & 0.76 & 0.72 & 0.75 & 0.76 & 0.75 & 0.76 & 0.77 & 0.80 & 0.77 & 0.73 & 0.79 & 0.78 & 0.80 & 0.76 & 0.78 & 0.81 & 0.76 & 0.72 & 0.79 & 1.00 & & & & & \\
\hline C2 & 0.77 & 0.77 & 0.78 & 0.80 & 0.76 & 0.76 & 0.75 & 0.79 & 0.70 & 0.74 & 0.80 & 0.76 & 0.77 & 0.78 & 0.79 & 0.80 & 0.74 & 0.78 & 0.79 & 0.83 & 0.78 & 0.76 & 0.80 & 0.78 & 0.73 & 0.78 & 0.81 & 1.00 & & & & \\
\hline C3 & 0.78 & 0.77 & 0.79 & 0.74 & 0.78 & 0.77 & 0.78 & 0.74 & 0.74 & 0.78 & 0.82 & 0.73 & 0.77 & 0.77 & 0.77 & 0.74 & 0.79 & 0.78 & 0.73 & 0.75 & 0.82 & 0.77 & 0.76 & 0.74 & 0.77 & 0.74 & 0.78 & 0.82 & 1.00 & & & \\
\hline C4 & 0.66 & 0.70 & 0.71 & 0.68 & 0.70 & 0.70 & 0.71 & 0.67 & 0.67 & 0.69 & 0.73 & 0.66 & 0.72 & 0.71 & 0.71 & 0.66 & 0.67 & 0.70 & 0.72 & 0.68 & 0.69 & 0.72 & 0.70 & 0.69 & 0.70 & 0.73 & 0.71 & 0.72 & 0.71 & 1.00 & & \\
\hline C5 & 0.75 & 0.75 & 0.75 & 0.75 & 0.77 & 0.74 & 0.75 & 0.73 & 0.73 & 0.75 & 0.78 & 0.77 & 0.79 & 0.81 & 0.83 & 0.78 & 0.74 & 0.77 & 0.79 & 0.78 & 0.77 & 0.79 & 0.79 & 0.76 & 0.72 & 0.78 & 0.84 & 0.83 & 0.79 & 0.75 & 1.00 & \\
\hline C6 & 0.72 & 0.73 & 0.75 & 0.76 & 0.71 & 0.72 & 0.74 & 0.75 & 0.70 & 0.71 & 0.75 & 0.77 & 0.75 & 0.76 & 0.79 & 0.77 & 0.72 & 0.76 & 0.76 & 0.81 & 0.75 & 0.76 & 0.77 & 0.77 & 0.72 & 0.77 & 0.79 & 0.81 & 0.75 & 0.69 & 0.84 & 1.00 \\
\hline
\end{tabular}


Table S1. Similarity coefficients among five lowland switchgrass cultivars. The ID for each plant genotype was denoted by a combination of letter and number. A, B, C, K, and P represented cultivars 'Alamo', ‘BoMaster', 'Cimarron', ‘Kanlow', and 'Performer', respectively (contd.)

\begin{tabular}{|c|c|c|c|c|c|c|c|c|c|c|c|c|c|c|c|c|c|c|c|c|c|c|c|c|c|c|c|c|c|c|c|c|}
\hline & A1 & A2 & A3 & A4 & A5 & A6 & A7 & A8 & A10 & A11 & A12 & A14 & A15 & B1 & B2 & B3 & B4 & B6 & B8 & B9 & B10 & B11 & B12 & B13 & B14 & B15 & $\mathrm{C} 1$ & C2 & C3 & C4 & C5 & C6 \\
\hline 7 & 74 & 76 & 0.77 & .77 & 73 & 75 & 77 & 77 & 0.70 & 76 & 74 & .72 & 74 & 76 & 0.75 & 0.77 & 0.75 & .76 & 74 & .77 & 0.74 & 0.74 & 0.77 & 0.75 & 0.72 & .73 & 0.78 & 0.80 & 0.78 & 0.65 & 0.80 & 0.78 \\
\hline 8 & & 30 & 0.82 & & & 77 & & & & & & & & & & & & & & & 76 & & & & & & 81 & 0.83 & 79 & 69 & 81 & 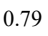 \\
\hline 9 & 0.73 & 77 & 80 & 0.80 & 5 & 76 & 79 & 77 & 69 & $\mathrm{~s}$ & 7 & 0.78 & 0.78 & 78 & 79 & 76 & 0.73 & 75 & 78 & 0.77 & 75 & 77 & 0.76 & 75 & 72 & 77 & 81 & 83 & 0.79 & .76 & 87 & 80 \\
\hline 10 & 0.72 & 75 & 75 & 0.80 & 13 & 76 & 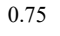 & 0.79 & 0.65 & 0.7 & & 0.7 & 0.73 & 0.70 & 73 & & & 0.73 & 3 & .80 & 74 & 72 & 0.74 & 14 & 0.67 & 13 & 80 & 82 & 0.75 & .66 & 19 & .79 \\
\hline 1 & & & & & & & & & & & & & & & & & & & & & & & & & & & & & & & .80 & 77 \\
\hline 12 & 74 & 77 & 78 & 0.78 & 78 & 78 & 79 & 76 & 0.74 & 0.7 & 0.79 & 0.74 & 78 & 77 & 79 & 0.76 & 0.76 & 0.77 & 78 & 0.77 & 79 & 0.78 & 0.79 & .75 & 74 & 75 & 82 & .83 & 0.83 & 0.73 & .81 & 0.78 \\
\hline 13 & 0.77 & 78 & 0.78 & 0.75 & 0.81 & 79 & 75 & 0.74 & 0.76 & 0.7 & 0. & 0. & 0.80 & 80 & 78 & 0.74 & 0.76 & 0.78 & 78 & .14 & 80 & 80 & 0.77 & 0.73 & 0.18 & .76 & 79 & 8.80 & 0.83 & 0.74 & 0.83 & 0.75 \\
\hline 14 & 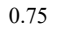 & 76 & 0. & & 0.14 & $1 / 4$ & 74 & & & & & & & & & & & 0.0 & & & & & & & & & & & 0.19 & 09 & .78 & 74 \\
\hline 15 & 73 & 73 & 74 & 0.73 & 0.73 & 71 & 71 & 0.74 & 0.70 & 0.69 & 0.73 & 0 & 76 & 0.79 & 0.83 & & 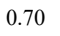 & 0.77 & 0.77 & 0.79 & 0.74 & 79 & 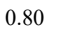 & 0.76 & 73 & .80 & 76 & 78 & 0.73 & 0.69 & 81 & 0.79 \\
\hline 16 & 0.73 & 75 & 0.78 & 0.74 & 0.72 & 73 & 75 & 0.73 & & 0.7 & & & 0 & 79 & & & & 0.7 & & 18 & 76 & 78 & 0. & 0.77 & .13 & 81 & 77 & .77 & 0.75 & 0.69 & .80 & 0.77 \\
\hline 17 & 14 & 0.75 & 0. & 0.73 & 0.71 & 75 & 73 & $1 / 2$ & & 0.7 & & 0.1 & 0.18 & 0.80 & 0.84 & & 0. & 0.7 & .80 & .18 & 0.16 & & & 0.76 & 0.1 & .82 & 0.18 & .18 & 0.15 & $0 . / 1$ & .01 & 0.77 \\
\hline 18 & 74 & 75 & 0.78 & & 71 & 0.75 & 74 & . & 0. & & & 0. & 078 & 0.83 & & & & 0.8 & & & & & & & & & & & & & & 78 \\
\hline 19 & 0.74 & 0.74 & 0.76 & 0. & 0. & 0.72 & 0. & & & & & & & & & & & 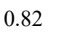 & & 31 & 77 & & & 0.80 & & 84 & 81 & 81 & 0.76 & .69 & 0.80 & 0.79 \\
\hline 20 & 14 & 0.74 & 0. & 0.75 & 0.72 & 0.74 & 72 & t & & & 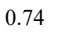 & م & 0.78 & 0.80 & 0. & & 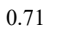 & 0 & .06 & 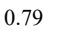 & 16 & & 0.8 & 10 & 0.15 & 1.81 & 19 & 78 & 0.73 & 0.68 & 79 & 78 \\
\hline 21 & 0.73 & 0.77 & 0.78 & & & 0.73 & 0.74 & 0.72 & 0. & & & & & & & & & & & & & & & & & & & & & & & 79 \\
\hline 22 & 0 & . & 0.76 & & & 0.72 & & & & & & & & & 31 & & & 0 & & & 75 & & & 0.7 & & 79 & 79 & .79 & 74 & 66 & 0.82 & 0.78 \\
\hline 23 & 75 & 75 & 0.75 & 0. & 0. & .73 & 71 & 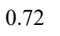 & & 0.7 & 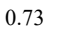 & 0.7 & 0.78 & 0.80 & 0.81 & 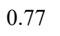 & 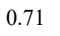 & 0.7 & 0.77 & 0.78 & 0.78 & 0.78 & 0.81 & 0.7 & 0.74 & .79 & 0.80 & 0.78 & 74 & 68 & 80 & .76 \\
\hline 24 & 73 & 76 & 18 & 0 . & & 0.75 & 0.75 & 0.75 & 0.6 & & & & 0.78 & & & & & 0 & & & 0.77 & & & & & & 8 & 80 & 4 & 0.70 & 78 & 0.74 \\
\hline 25 & & & & & & & & & & & & & & & & & & & & & & & & & & & & & & & & 77 \\
\hline K26 & 71 & 72 & 0.74 & 0.71 & 0.6 & 0.69 & 72 & 0.70 & 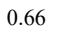 & 0.69 & 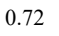 & 0. & 0.76 & 0.77 & 0.79 & & 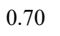 & 0 & 0.76 & 0.77 & 0.72 & 0. & 0.79 & 0.76 & 0.74 & 0.80 & 0.79 & 76 & 0.72 & 0.67 & 79 & 0.76 \\
\hline D) & 0.77 & 0.74 & 0.75 & 0.71 & 0 & 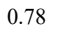 & 0.73 & 0.71 & 6 & & & & 0.80 & & 0. & & & & & & 1 & 31 & & & & & 19 & 8 & 19 & 70 & 19 & 76 \\
\hline & & & & & & & & & & & & & & & & & & & & & & & & & & & & & & & & . \\
\hline 3 & 0.76 & . & 0.76 & 0.74 & 0.79 & 0.7 & 73 & 0 & & & & & 0.78 & 0.83 & 0.78 & 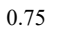 & & 0 & 0.78 & 0.77 & 0.79 & 0.78 & & 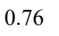 & 0.76 & 0.76 & .75 & 0.79 & 0.78 & 0.69 & 76 & 0.74 \\
\hline 4 & 0.67 & 63 & 0. & 0.60 & 0.72 & 0.70 & 0.64 & 0.63 & . & 0. & . & 0. & 0.6 & 0.65 & 0. & 0 & 0 & 0 & 0.68 & 0.65 & 70 & 71 & 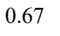 & 0. & 0.70 & 0.66 & 65 & 5 & 67 & 69 & 66 & 0.63 \\
\hline & & & & & & & & & & & & & & & & & & & & & & & & & & & & & & & & 71 \\
\hline 6 & 0 & & & & & 0. & & & & & & & & & & & & & & & & & & & & & & & & & 2 & 69 \\
\hline 8 & 0.69 & 63 & 0.65 & 0.61 & 76 & 0.72 & 0.63 & 0.64 & 0.7 & 0. & 0. & 0.6 & 0.68 & 0.72 & 0. & 0. & 0 & 0 & 0.70 & 0.66 & 73 & 71 & . & 0.64 & 0.71 & 0.65 & 65 & 68 & 0.70 & 66 & 67 & 0.62 \\
\hline 13 & & & & & & $7-$ & & & & & & & & & & & & & & & & & & & & & & & 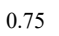 & & .78 & 17 \\
\hline & & & & & & & & & & & & & & & & & & & & & & & & & & & & & & & 78 & 73 \\
\hline 15 & 0.72 & 70 & 0.71 & 0.66 & 0.76 & 0.70 & 0.67 & 0.65 & 0.7 & 0.70 & 0.75 & 0.7 & 0.79 & 0.77 & 0. & . & 0. & 0.7 & 0.75 & 0.72 & 0.78 & 78 & 76 & 2 & .80 & 77 & 71 & 71 & 73 & 0.70 & .74 & 0.69 \\
\hline 16 & 0.73 & 0.78 & 0.78 & 0.73 & 0.7 & 0.73 & 0.76 & 77 & & 0.7 & 0.7 & 0.7 & 0.7 & 0.78 & 0.7 & 0.78 & 0.7 & 0.76 & 0.7 & 180 & 0.75 & $0.7 / 2$ & 0.77 & 0.77 & & .78 & 0.78 & .78 & 76 & 0.65 & 78 & 0.75 \\
\hline 7 & & & & & & & & & & & & & & & & & & & & & & & & & & & & & .73 & .68 & .76 & 0.15 \\
\hline
\end{tabular}


Table S1. Similarity coefficients among five lowland switchgrass cultivars. The ID for each plant genotype was denoted by a combination of letter and number. A, B, C, K, and P represented cultivars 'Alamo', 'BoMaster', 'Cimarron', 'Kanlow', and 'Performer', respectively.

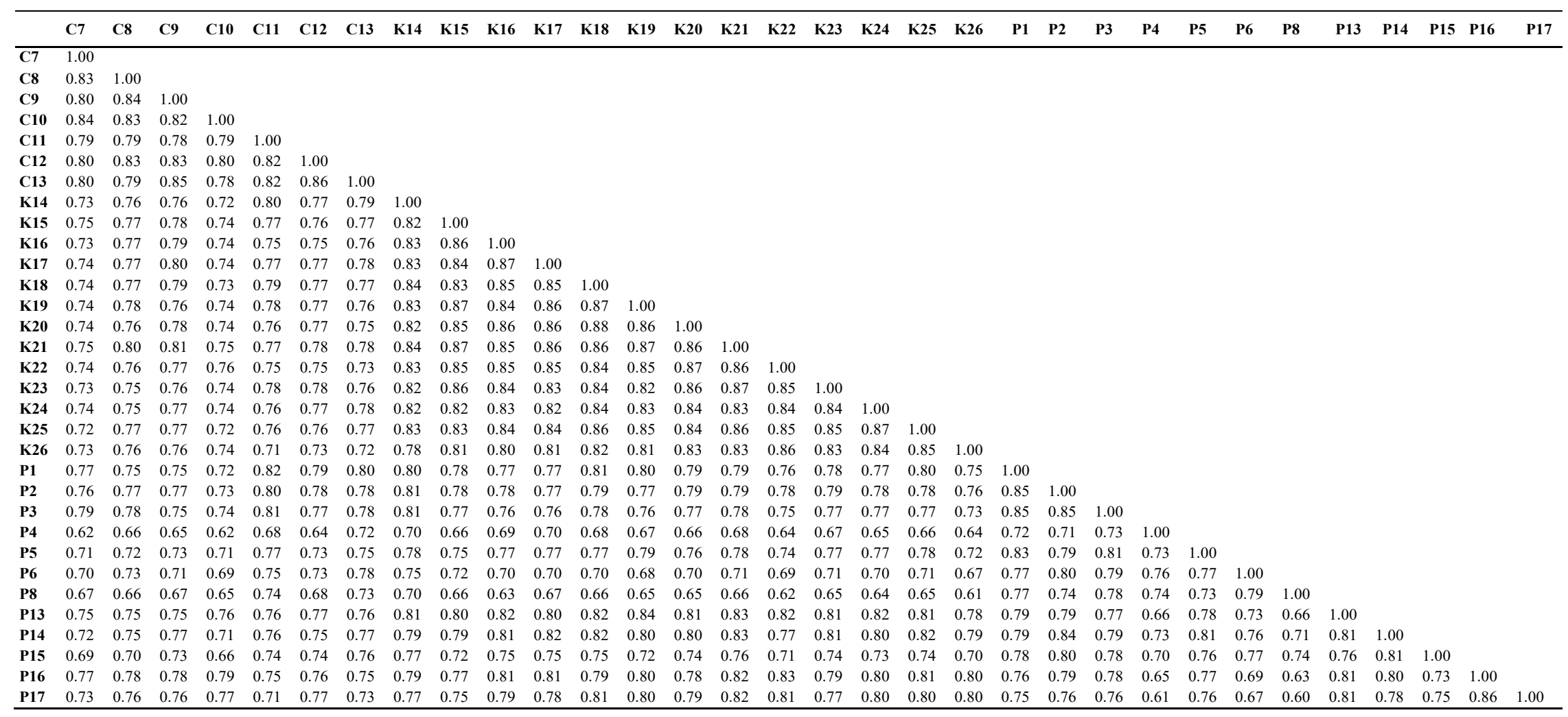


Table S2. Mantel's test. Criteria for goodness of fit of the dendrogram to dissimilarity matrix: $r \geq 0.90$ very good fit, $0.9>\mathbf{r} \geq 0.80$ good fit, $0.80>$ $r \geq 0.70$ poor fit, and $r<0.70$ very poor fit (Rohlf, 1998).

\begin{tabular}{|c|c|c|c|c|c|c|}
\hline Tests for association & $\begin{array}{l}\text { Among } \\
\text { cultivars }\end{array}$ & Alamo & BoMaster & Cimarron & Kanlow & Performer \\
\hline Matrix correlation (r) & 0.77 & 0.95 & 0.96 & 0.89 & 0.76 & 0.82 \\
\hline \multicolumn{7}{|l|}{ (= normalized Mantel statistic Z) } \\
\hline Approximate Mantel t-test (t) & 10.25 & 8.04 & 8.16 & 8.44 & 8.39 & 9.25 \\
\hline Probability random $\mathrm{Z}<$ observed $\mathrm{Z}(P)$ & 1.00 & 1.00 & 1.00 & 1.00 & 1.00 & 1.00 \\
\hline Goodness of fit of the dendrogram to the original dissimilarity matrix & Poor & Very good & Very good & Good & Poor & Good \\
\hline
\end{tabular}

Table S3. Pairwise Nei's (1972) genetic distance in five lowland switchgrass cultivars.

\begin{tabular}{lllll}
\hline & Alamo & BoMaster & Cimarron & Kanlow \\
\hline BoMaster & 0.051 & & & \\
Cimarron & 0.047 & 0.057 & & \\
Kanlow & 0.089 & 0.061 & 0.072 & 0.088 \\
Performer & 0.062 & 0.058 & 0.071 & \\
\hline
\end{tabular}

